\title{
Nanoclay and Temperature Effects on Carbon/Fiberglass Composite Laminates under Impact Loading
}

\author{
H.Y. UnAL ${ }^{a, *}$, G. ONER ${ }^{b}$ AND Y. PEKBEY ${ }^{a}$ \\ ${ }^{a}$ Ege University, Department of Mechanical Engineering, 35100 Izmir, Turkey \\ ${ }^{b}$ Ataturk University, Vocational School, Automotive Program, 25240 Erzurum, Turkey
}

\begin{abstract}
In the current study the experimental investigations of hybrid carbon/fiberglass composite laminates subjected to impact loading at room and elevated temperatures were carried out to determine the effect of nanoclay addition into the epoxy resin. Hybrid laminates were fabricated with plain weave carbon fabric and plain weave E-glass fabric using hand layup method. The epoxy matrix with $0 \%, 0.5 \%, 0.75 \%$, and $1.25 \%$ of nanoclay reinforcement by weight was produced using an ultrasonic mixer. The laminates were then subjected to low-velocity impact tests with energies between 20 and $45 \mathrm{~J}$. The penetration and perforation thresholds of hybrid composites with and without nanoclay were obtained by using energy profile diagram, force-displacement and energy-time curves. Experimental results show that the impact performance of carbon/fiberglass composite laminates was changed with the nanoclay addition. Impact performance of these composites was also affected by the considered range of temperatures.
\end{abstract}

DOI: 10.12693/APhysPolA.134.159

PACS/topics: temperature effect, nanoclay, low-velocity impact, hybrid laminate

\section{Introduction}

Composite materials are sensitive to impact damage, even if these are low velocity impacts, since impacts affect the performance of the composite materials. On the other hand, these materials are used at different temperatures. For this reason, these two parameters should be studied at operational conditions.

Carbon and glass fibre-reinforced hybrid polymer composites are widely used in aerospace industry because of their high specific stiffness and strength. Nanocomposites are advanced multifunctional class of materials, utilized in numerous engineering and commercial areas. Addition of small amounts of nanoparticles can improve the strength of the pure matrix by creating a large interface area in a nanocomposite. Studies performed by many researchers show that the addition of low concentrations of nanoparticles into polymers leads to great performance enhancements of mechanical and thermal properties [1-6].

Many studies have been performed concerning the effect of temperature on the impact response of composite laminates. However, very few studies can be found investigating the effect of nanoparticles on the impact performance. For this purpose, in this study, carbon/glass hybrid laminates containing nanoclay modified epoxy matrix were subjected to low velocity impact tests, performed at different impact energies and temperatures.

The focus of this research was to improve the impact properties and to minimize the absorbed energy as a result of addition of nanoclay. Impact tests were

*corresponding author; e-mail: hasan.yavuz.unal@ege.edu.tr conducted at different temperatures to obtain information about peak reaction force, penetration threshold and absorbed energy.

\section{Materials and test methods}

Carbon $\left(245 \mathrm{~g} / \mathrm{m}^{2}\right)$ and glass $\left(200 \mathrm{~g} / \mathrm{m}^{2}\right)$ fibres and epoxy resin were used in this study. The organo modified nanoclay, manufactured by Eczacıbaşı (Turkey), was used as the additive to the epoxy resin.

Hybrid epoxy laminates, reinforced with carbon and glass fiber, with various weight fractions of nanoclay, were prepared by hand layup method. Processing of laminate consisted of two steps. In the first step nanoclays were mixed with the epoxy resin. In the second step the modified resin was infused into the carbon and glass fiber roving. Hielscher UP400S ultrasonic machine was used for dispersion of nanoclays of various weight percentages $(0,0.5,0.75$ and $1.25 \%)$ in the epoxy.

After mixing the resin with the nanoclay, the epoxy resin-nanoclay solution was cooled to room temperature. Then followed the laminate making process. The epoxy resin-nanoclay solution was carefully poured onto carbon and glass fibres. Spreading of resin was performed using a hand roller to produce prepreg fabrics, as shown in Fig. 1a and b.

Fifteen ply laminates were stacked with top 1-5 layers being of carbon fiber, core $6-10$ layers being of glass fiber and bottom 11-15 layers being of carbon fiber on teflon sheet. The molded laminates were exposed to a pressure of 10 bar in a hydraulic hot press, as shown in Fig. 1c, and then were heated up to $125^{\circ} \mathrm{C}$. Plates were kept at $125^{\circ} \mathrm{C}$ for $1 \mathrm{~h}$ and then cooled down to room temperature. Finally, the parts were taken out from the mold. The specimens were cut from these thin plates using abrasive water jet cutter. 

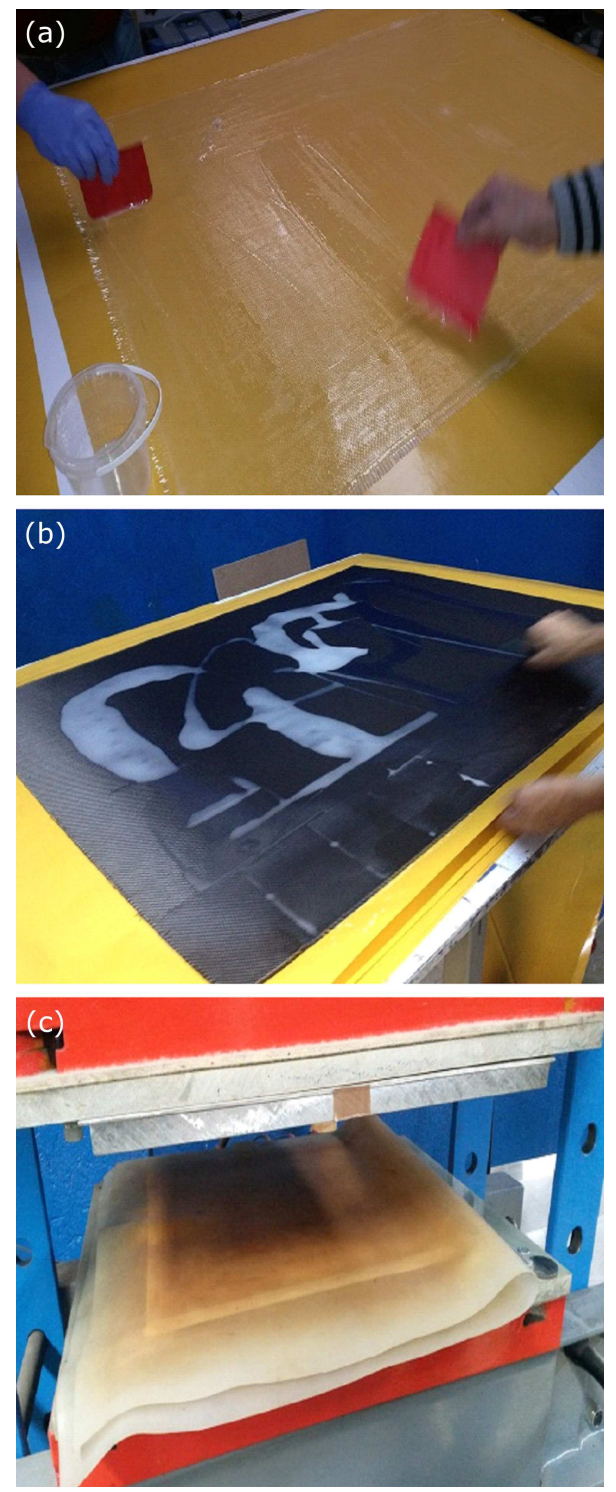

Fig. 1. The epoxy resin-clay infusion into glass fiber (a), carbon fiber (b). Image of hydraulic hot press (c).

Impact tests were done according to ASTM D562810 standard [7]. Impact tests were carried out on $100 \times 100 \mathrm{~mm}^{2}$ square samples with thickness of $3 \mathrm{~mm}$ at room temperature and at $50{ }^{\circ} \mathrm{C}$ on Fractovis Plus test machine. The test machine was equipped with a thermally controllable enclosure to allow testing at various temperatures. The impactor had hemispherical geometry, $12.7 \mathrm{~mm}$ in diameter and had a mass of $4.926 \mathrm{~kg}$.

The impactor was impacting on the center of a specimen, the edges of which were firmly fixed between two circular rings, having a test window of $76 \mathrm{~mm}$ in diameter. The incident impact energy was altered by changing the height of the impactor relative to the specimen. In this way, the displacement of impactor could be used to achieve 20, 30 and $45 \mathrm{~J}$ of energy. At least three specimens were tested to provide test repeatability for each condition at $23^{\circ} \mathrm{C}$ and $50^{\circ} \mathrm{C}$.

\section{Results and discussion}

Figures 2, 3 and 4 show typical force-displacement, energy-time and energy profile diagram of specimens, respectively, for impact energies of 20, 30 and $45 \mathrm{~J}$.

Evaluation of force-displacement data obtained at room temperature shows that the increasing nanoclay content results in the higher peak reaction force at all impact energy levels. The peak reaction force can be identified with the resistance to impact load. Specimens, in which the matrix was modified with nanoclay, withstood higher impact force than the pure specimen. In Fig. 2a, the highest peak reaction force was seen in laminate containing 1.25 wt.\% of nanoclay, which was $16 \%$ higher than that of pure specimen.

On the contrary, the displacement values were decreased with increasing nanoclay content. This means that impact energy was absorbed in smaller deformations. Pure specimen has shown the highest deformation among all studied specimens. Its maximum deformation was around $5.91 \mathrm{~mm}$. The displacement value decreased gradually with increasing nanoclay content. Displacement value of specimen containing $1.25 \mathrm{wt} . \%$ of nanoclay was around $8 \%$ lower than that of pure specimen.

For impact of $20 \mathrm{~J}$ all specimens have shown rebounding effect. Specimens have absorbed the impact energy and then the impactor left the specimens surface. The reaction force of specimen containing $1.25 \mathrm{wt} . \%$ nanoclay has shown a sharp fall after the peak and has return to origin with narrow distance to loading part. However, in the pure specimen and in the specimen containing 0.5 wt. $\%$ of nanoclay, the force difference between peak point and after peak point was small. This means that these specimens took more damage and approached the penetration situation.

When impact energy was increased to $30 \mathrm{~J}$, similar results were obtained. The specimen containing 1.25 wt.\% of nanoclay has shown the highest peak reaction force. However the peak reaction force was decreased by around $350 \mathrm{~N}$, compared to previous test, but was still $8 \%$ higher than that of the pure specimen. In other three specimens (0 wt.\%, 0.5 wt. $\%$ and 0.75 wt. $\%$ ) the peak reaction forces were increased, compared to the previous test.

The maximum displacements of all specimens were increased compared to $20 \mathrm{~J}$ test. The highest increase was seen in pure specimen and specimens containing $0.5 \mathrm{wt} . \%$ of nanoclay, which were increased by around $72 \%$ and $80 \%$, respectively.

Two different graph ends were seen in the forcedisplacement curves of Fig. 2c. Specimens containing 1.25 wt. $\%$ and 0.75 wt. $\%$ of nanoclay have shown rebounding, while the pure specimen and specimen with 0.5 wt. $\%$ of nanoclay have shown penetration.

When the impact energies were increased to $45 \mathrm{~J}$, the peak reaction forces of all specimens increased. Peak force has decreased only for pure specimen by about $150 \mathrm{~N}$, compared to previous test. The highest peak reaction force of around $5600 \mathrm{~N}$ was 
seen in specimen with 1.25 wt.\% of nanoclay. According to Fig. 2e for all four specimens the tips of the curves ended up with large displacement and the specimens were perforated.

When force-displacement data was measured at $50^{\circ} \mathrm{C}$, the difference between the peak reaction forces of pure and nanoclay containing specimens decreased compared to the tests done at room temperature.

At $20 \mathrm{~J}$ impacts all specimens have shown rebounding type force-displacement curves, which can be seen in Fig. 2b. The highest reaction force was measured in specimen containing $1.25 \mathrm{wt} . \%$ of nanoclay, but the difference between 1.25 and 0.5 wt.\% was only $20 \mathrm{~N}$. The lowest value, which was around $4900 \mathrm{~N}$, was seen in the pure specimen. Peak reaction forces of 0.75 and 1.25 wt.\% nanoclay containing specimens were decreased compared to tests done at room temperature.
The peak reaction forces of other two specimens were nearly similar to those obtained at room temperature.

While pure and 0.5 wt.\% nanoclay containing specimens have shown penetration type curves, specimens with 0.75 and 1.25 wt.\% of nanoclay were perforated in $30 \mathrm{~J}$ impacts, as shown in Fig. 2d. The increase of test temperature by nearly $30^{\circ} \mathrm{C}$ has caused a significant decrease of penetration and perforation threshold.

Specimen with 0.5 wt.\% of nanoclay has shown the highest peak reaction force. The increment compared to peak reaction force of pure specimen was $7 \%$. All specimens were perforated when test energies were increased to $45 \mathrm{~J}$. Specimen containing 0.5 wt.\% of nanoclay has shown the highest reaction force in Fig. 2f. For specimen with 1.25 wt.\% of nanoclay the oscillating reaction force means that the specimen took more damage, compared to others.
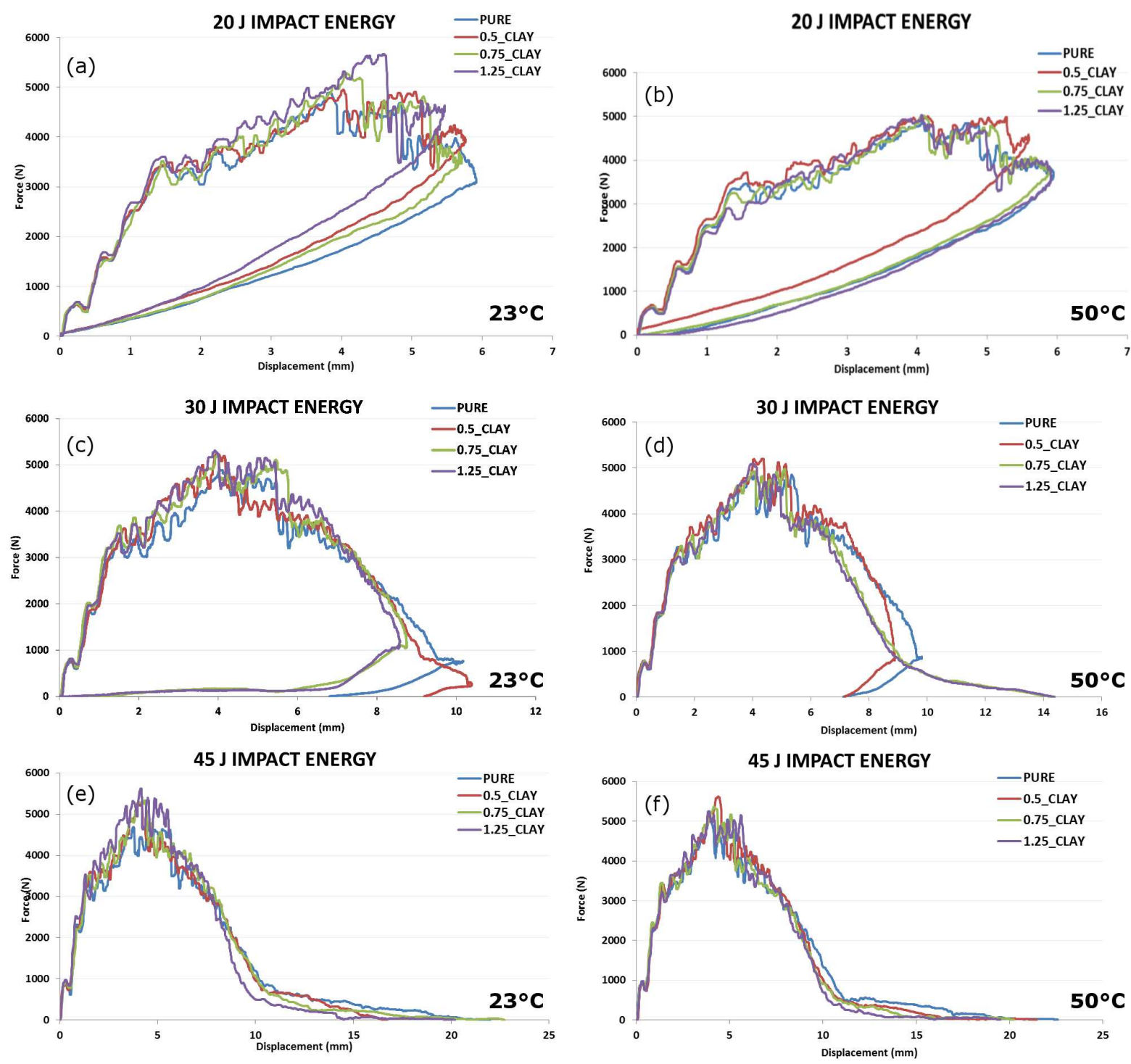

Fig. 2. Effect of nanoclay on the force vs displacement curves of samples impacted with energy of $20 \mathrm{~J}$ (a), $30 \mathrm{~J}$ (c) and $45 \mathrm{~J}(\mathrm{e})$ at $23^{\circ} \mathrm{C}$ and $20 \mathrm{~J}(\mathrm{~b}), 30 \mathrm{~J}(\mathrm{~d}), 45 \mathrm{~J}(\mathrm{f})$ at $50^{\circ} \mathrm{C}$. 

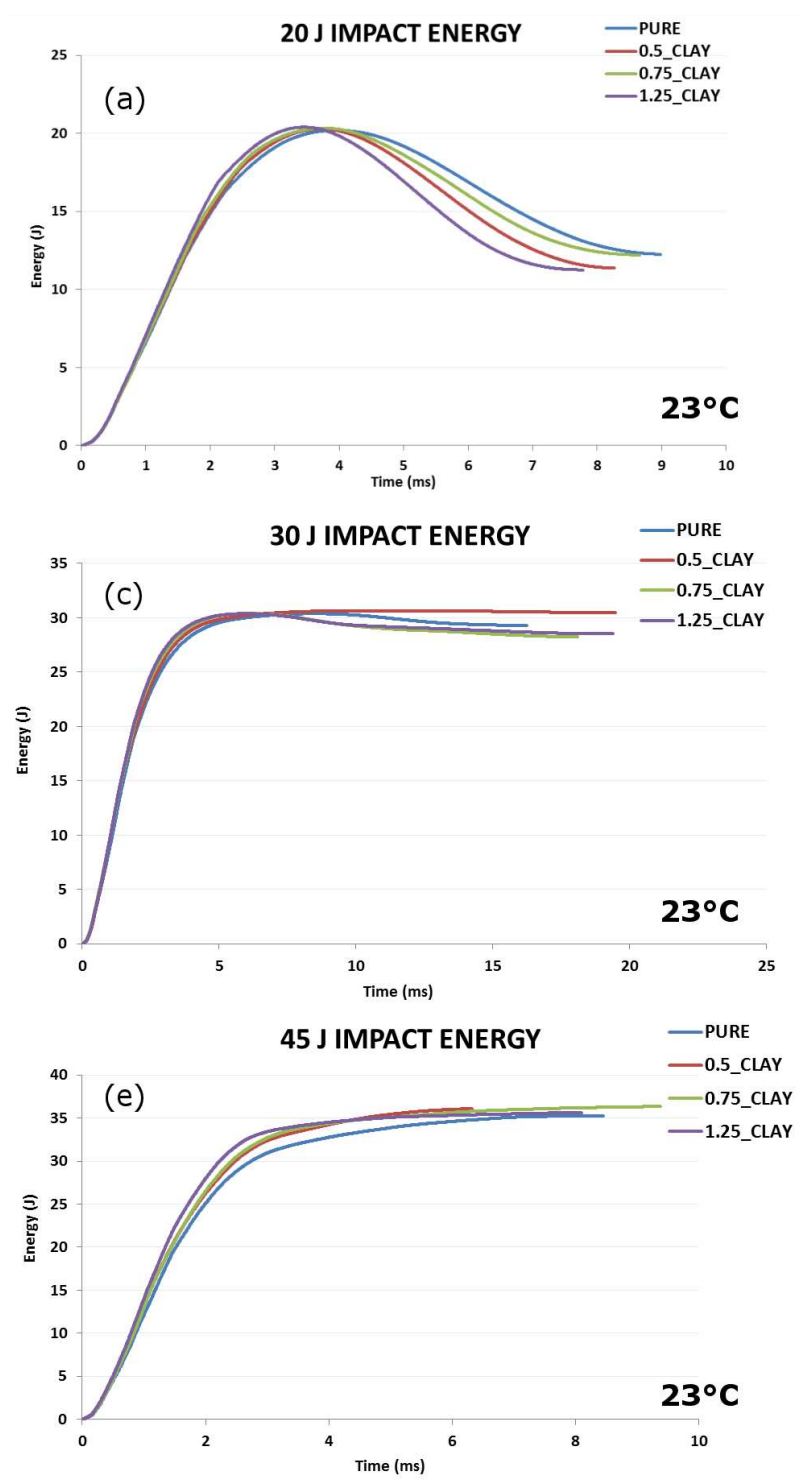

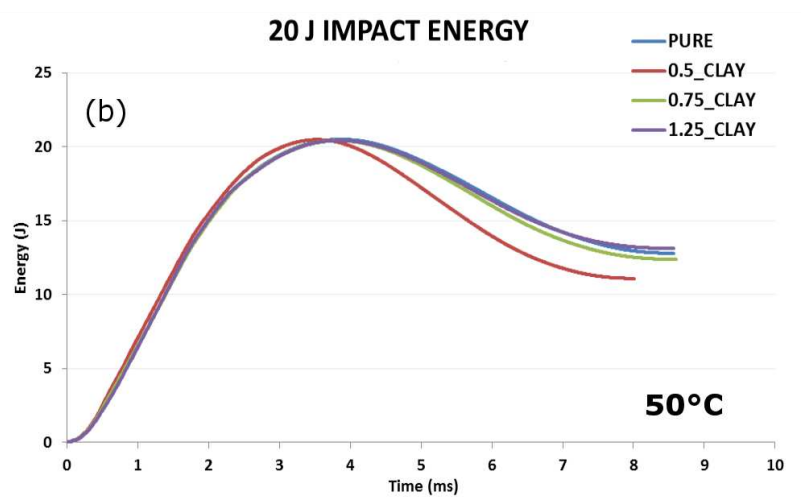

30 J IMPACT ENERGY
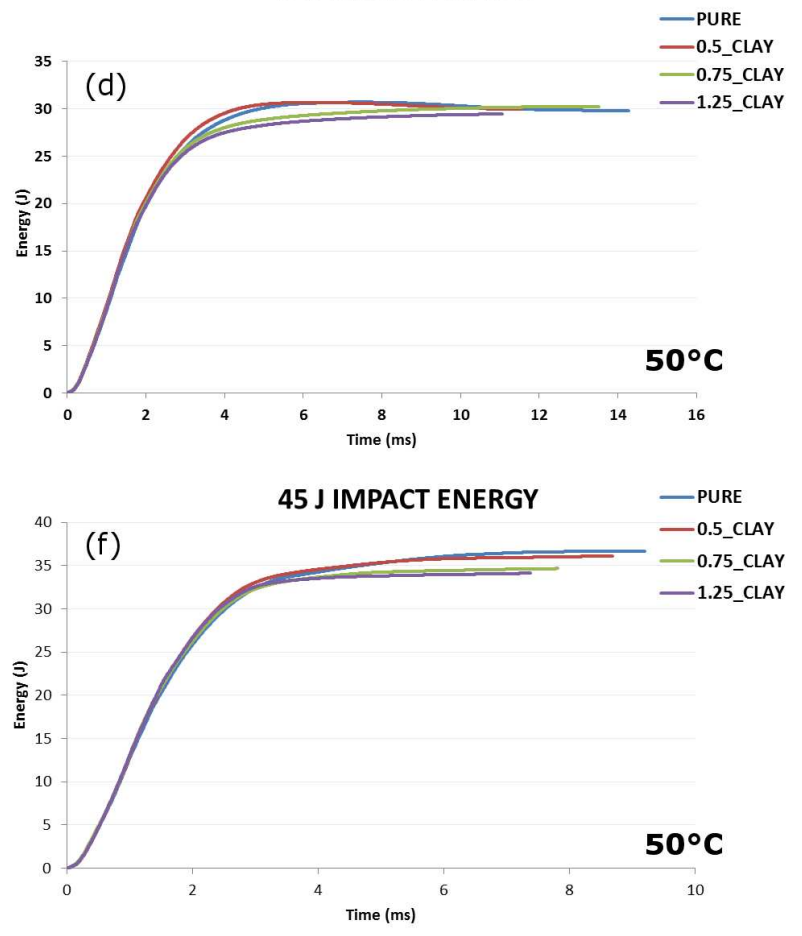

Fig. 3. Effect of nanoclay on the energy vs time curves of samples impacted with energy of $20 \mathrm{~J}$ (a), $30 \mathrm{~J}$ (c) and $45 \mathrm{~J}$ (e) at $23^{\circ} \mathrm{C}$ and $20 \mathrm{~J}(\mathrm{~b}), 30 \mathrm{~J}(\mathrm{~d})$ and $45 \mathrm{~J} \mathrm{(f)}$ at $50^{\circ} \mathrm{C}$.

Energy-time graphs of specimens are in a good agreement with the force-displacement plots. At $20 \mathrm{~J}$ impacts, 1.25 and 0.5 wt.\% nanoclay containing specimens have absorbed the least energy at room temperature and at $50^{\circ} \mathrm{C}$, respectively. Absorbed energy was defined by the plateau located after the peak in the energy-time curves. In both Fig. 3a and b all specimens show elastic energy which was found by substituting absorbed energy from impact energy. Elastic energies were used for rising up the impactor from the surface of specimens.

When impact energy increased to $30 \mathrm{~J}$, for specimen with 0.5 wt.\% of nanoclay the absorbed energy value remained constant after reaching the maximum value at both temperatures in Fig. 3c and d. The end of the impactor was stuck in the specimen in this case.

Specimens containing 0.75 and 1.25 wt. $\%$ of nanoclays have shown elastic energy at room temperature, but they have not shown any elastic energy at $50{ }^{\circ} \mathrm{C}$ and were perforated. In fact the specimen with $1.25 \mathrm{wt} . \%$ of nanoclay could not reach the impact energy at $50^{\circ} \mathrm{C}$ and absorbed around $29 \mathrm{~J}$. Pure specimen has absorbed $29 \mathrm{~J}$ at room temperature with displaying the elastic energy, but at $50^{\circ} \mathrm{C}$ the impactor end was stuck after the test was finished.

In a perforated specimen, the highest absorbed energy is preferred. At impacts with energy of $45 \mathrm{~J}$ in Fig. 3e and $\mathrm{f}$, all specimens were perforated at both temperatures. Pure specimen and specimen with 0.5 wt.\% of nanoclay absorbed the highest impact energy at $50^{\circ} \mathrm{C}$ and at room temperature, respectively.

Energy profile diagrams were drawn for identifying penetration and perforation thresholds. When absorbed energy coincided with equal line, the penetration threshold occurred. From Fig. 4, the penetration threshold de- 
(a) Energy Profile Diagram

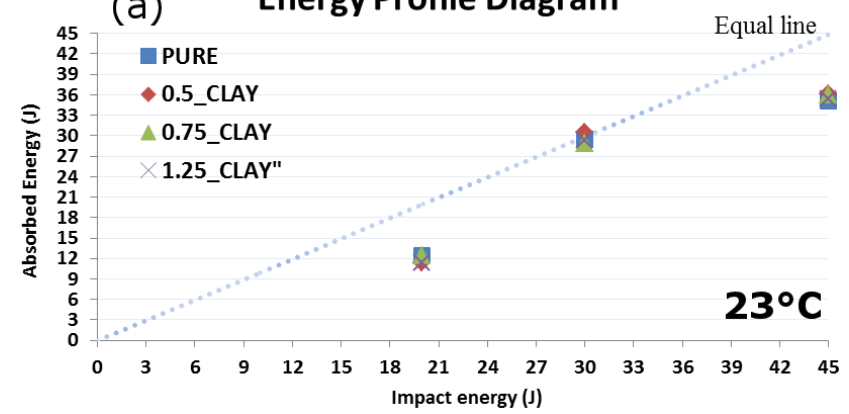

(b)

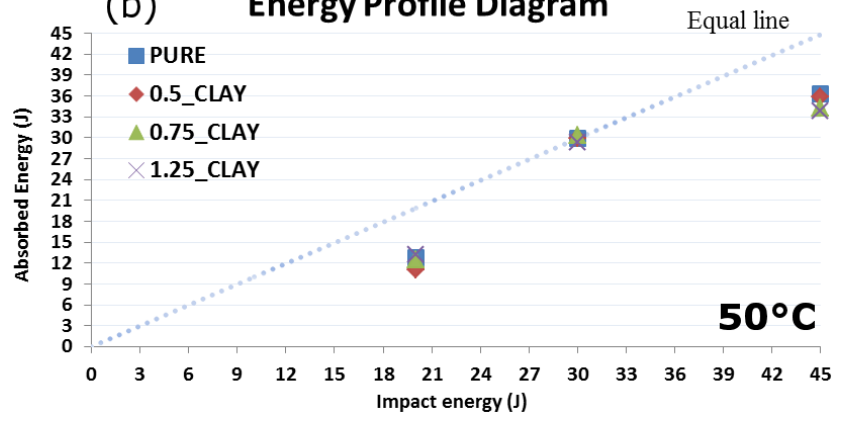

Fig. 4. Effect of nanoclay on the energy profile diagram of samples impacted with energy of $20 \mathrm{~J}, 30 \mathrm{~J}$ and $45 \mathrm{~J}$ at $23^{\circ} \mathrm{C}$ (a) and at $50{ }^{\circ} \mathrm{C}(\mathrm{b})$.

creased with increasing test temperature. According to figures, it is difficult to be certain about the penetration energy for the specimens. In terms of force-displacement and energy-time graphs, in the pure specimen and specimen with 0.5 wt. \% of nanoclay the penetration thresholds should be $30 \mathrm{~J}$ at both temperatures. In specimens with 0.75 and 1.25 wt.\% of nanoclay the penetration thresholds should be between 30 and $45 \mathrm{~J}$ at room temperature and between 20 and $30 \mathrm{~J}$ at $50^{\circ} \mathrm{C}$.

\section{Conclusions}

In this study, low velocity impact tests at different temperatures were carried out to characterize how the addition of nanoclay to the epoxy would affect the maximum impact force and the absorbed energy of studied laminates. The results show that the addition of 1.25 wt. $\%$ and 0.5 wt.\% of nanoclay caused the highest reaction force and the lowest absorbed energy at room temperature and at $50^{\circ} \mathrm{C}$, respectively. It was found that the maximum reaction force of carbon/glass/epoxy hybrid laminates increased with increasing nanoclay concentration at room temperature. The best results were obtained in specimen containing $0.5 \mathrm{wt} . \%$ of nanoclay at $50{ }^{\circ} \mathrm{C}$. The penetration threshold decreased with increasing test temperature. Results of this study indicate that the addition of nanoclay leads to an improved impact resistance of hybrid laminate.

\section{Acknowledgments}

This research has been supported by the Scientific Research Project of Atatürk University of Turkey (BAP). Project number: BAP 2016/139.

\section{References}

[1] K. Iqbal, S.U. Khan, A. Munir, J.K. Kim, Compos. Sci. Technol. 69(11-12), 1949 (2009).

[2] P.N.B. Reis, J.A.M. Ferreira, Z.Y. Zhang, T. Benameur, M.O.W. Richardson, Compos. Part B: Eng. 46, 7 (2013).

[3] A.M. Amaro, P.N.B. Reis, M.A. Neto, Compos. Part B: Eng. 98, 23 (2016).

[4] M.H. Meybodi, S.S. Samandari, M. Sadighi, Compos. Sci. Technol. 133, 70 (2016).

[5] A. Rafiq, N. Merah, R. Boukhili, M. Al-Quadhi, Poly. Test. 57, 1 (2017).

[6] H.Y. Unal, Y. Pekbey, 2nd International Conference of Mechanics of Composites, 2016.

[7] ASTM D5628-10, Standard Test Method for Impact Resistance of Flat, Rigid Plastic Specimens by Means of a Falling Dart (Tup or Falling Mass), ASTM International, West Conshohocken, PA 2010. 